\title{
Major clinical research advances in gynecologic cancer in 2010
}

\author{
Dong Hoon Suh ${ }^{1}$, Jae Weon Kim ${ }^{1}$, Kidong Kim², Soon-Beom Kang ${ }^{1}$ \\ Department of Obstetrics and Gynecology, ${ }^{1}$ Seoul National University College of Medicine, \\ ${ }^{2}$ Korea Cancer Center Hospital, Korea Institute of Radiological and Medical Sciences, Seoul, Korea
}

\begin{abstract}
This review summarizes 11 major clinical research advances in gynecologic oncology in 2010. For ovarian cancer, bevacizumab as a leading molecular targeted agent, pegylated liposomal doxorubicin in recurrent disease, the role of neoadjuvant chemotherapy in an advanced setting, an effective screening method, and ARID1A mutations as a clue to the origin of clear cell carcinoma are mentioned. For cervical cancer, confirmation of the efficacy and the introduction of a self collection method of the human papillomavirus (HPV) test, and the association between the HPV vaccine and miscarriage are examined. For endometrial cancer, the superiority of laparoscopy in staging operation, the role of vaginal brachytherapy in an adjuvant setting, and the effect of para-aortic lymph node dissection are reviewed. In addition, the trend of geriatric oncology and chemotherapy in carcinosarcomas is also assessed.
\end{abstract}

Key Words: Bevacizumab, Ovarian cancer screening, Geriatric oncology

\section{INTRODUCTION}

The most outstanding advances in the field of gynecologic oncology in 2010 were not groundbreaking discoveries of brand-new concepts of management, but the final or interim results of existing studies. Extensive research has been being carried out into bevacizumab (BEV), which is currently one of the most promising targeted agents and the best combination of the conventional chemotherapeutic agents.

Similar to last year, ${ }^{1}$ the major journals were searched for these topics. The abstracts that were presented at the Society of Gynecologic Oncologists (SGO) Annual Meeting, the American Society of Clinical Oncology (ASCO), the European Society for Medical Oncology (ESMO) Annual Congress, and the International Gynecologic Cancer Society (IGCS) Biennial Meeting were reviewed for the publication of influential randomized clinical trials.

In addition, we referred to online news such as USAtoday (www.usatoday.com/news/health) and Time (www.time. com/time/health), which provided some indications when the topic of ovarian cancer screening was chosen. Finally, geriatric oncology was also selected as a topic of this review because it is expected to become increasingly important with the

Received December 7, 2010, Accepted December 7, 2010

Correspondence to Soon-Beom Kang

Department of Obstetrics and Gynecology, Seoul National University College of Medicine, 28 Yeongeon-dong, Jongno-gu, Seoul 110-744, Korea

Tel: 82-2-2072-3384, Fax: 82-2-762-3599

E-mail: ksboo308@gmail.com rapid growth of the elderly population, even though there were no major publications or presentations in the field of geriatric oncology in 2010.

This review not only summarizes the remarkable research achievements in gynecologic cancer in 2010, but also proposes a direction of research in the future.

\section{MAJOR CLINICAL RESEARCH ADVANCES}

\section{Bevacizumab, the leading molecular targeted agent for ovarian cancer}

Several phase III randomized controlled trials (RCTs) in ovarian cancer have been carried out since phase II trials demonstrated the activity of BEV as a single agent and in combination with other modalities, such as low-dose metronomic cyclophosphamide. $^{2-5}$ Among them, two key first-line studies, Gynecologic Oncology Group (GOG) 218 and International Collaborative Ovarian Neoplasm (ICON) 7, reported their preliminary findings at the 2010 ASCO Annual Meeting (abstract LBA1) and the 35th ESMO Congress (abstract LBA4), respectively. ${ }^{6,7}$

GOG 218 is a study of 1,873 patients. The control group (arm $\mathrm{I}, \mathrm{n}=625$ ) received the standard treatment with 6 cycles of carboplatin (AUC 6) and paclitaxel $\left(175 \mathrm{mg} / \mathrm{m}^{2}\right)$. There were two experimental groups, one (arm II, $n=625$ ) received BEV (15 mg/kg every 3 weeks) only during the same chemotherapy, switching to three-weekly placebo infusions for 1 year, which was also administered throughout treatment in the control group. The second group (arm III, $n=623$ ) received BEV during chemotherapy and for a further 16 cycles of maintenance, leading to a total of 16 months of therapy. The 
patients included those who had undergone maximal debulking surgery: stage III optimal (macroscopic residual disease $\leq$ $1 \mathrm{~cm}$ ) or suboptimal $(>1 \mathrm{~cm})$, or stage IV epithelial ovarian (EOC), primary peritoneal (PPC) or fallopian tube cancer (FTC), without prior chemotherapy. GOG 218 met the primary objective as the front-line treatment of advanced ovarian cancer. The progression free survival (PFS) with paclitax$\mathrm{el} /$ carboplatin plus BEV followed by BEV maintenance (arm III) was significantly superior to that of paclitaxel/carboplatin alone (arm I) (hazard ratio [HR], 0.717; 95\% confidence interval [CI], 0.625 to $0.824 ; \mathrm{p}<0.0001$ ), but PFS with paclitax$\mathrm{el} /$ carboplatin plus BEV without maintenance (arm II) was not (HR, 0.908; 95\% CI, 0.759 to $1.040 ; \mathrm{p}=0.080$ ). The limited overall survival (OS) analysis at the time of the final PFS analysis failed to show any OS improvement both in arms II (HR, 1.036; 95\% CI, 0.827 to $1.297 ; \mathrm{p}=0.361)$ and III (HR, $0.915 ; 95 \% \mathrm{CI}, 0.727$ to $1.152 ; \mathrm{p}=0.252){ }^{8}$

In ICON 7 , the eligible patients were 1,528 women with high-risk early (stage I or IIA, grade 3 or clear cell histology $\leq$ $10 \%$ ) or advanced (stage IIB-IV) EOC, PPC or FTC. The patients were randomized to either 6 cycles of 3 weekly carboplatin (AUC 6) and paclitaxel $\left(175 \mathrm{mg} / \mathrm{m}^{2}\right)$ alone (control group, $n=764)$, or to the same chemotherapy with BEV (7.5 $\mathrm{mg} / \mathrm{kg}$ ) for 6 cycles followed by maintenance BEV for an additional 12 cycles every 3 weeks or until progression, whichever came first (research group, $n=764$ ). The research group showed a longer PFS than the control group (HR, 0.81; 95\% CI, 0.70 to $0.94 ; \mathrm{p}=0.0041)$. Preliminary OS data revealed 1 -year survival rates of $93 \%$ and $95 \%$ in the control and experimental group, respectively (HR, $0.81 ; 95 \% \mathrm{CI}, 0.63$ to 1.04; $\mathrm{p}=0.098$ ), even though longer term PFS and mature OS results are anticipated in 2012.

In both studies, adverse events were consistent with previous $\mathrm{BEV}$ studies and the treatment was well tolerated with no new safety concerns. ${ }^{2,4,9}$ Despite the difference in the stage composition in the eligible criteria and dose of BEV, GOG 218, and ICON 7 reported comparable PFS and preliminary OS results. The treatment effects in ICON 7 were numerically greater in the advanced-stage (stage III suboptimal and stage IV with debulking) patients (HR, 0.68; $95 \% \mathrm{CI}, 0.55$ to 0.85 ; $\mathrm{p}<0.001)$. Although the long term OS, quality of life, and other translational research results are soon to be released, patients diagnosed with an advanced stage are expected to receive substantial benefit from the addition of BEV.

Another BEV study in recurrent ovarian cancer, GOG 213, is also underway. This study is a phase III RCT of paclitaxel/carboplatin alone or in combination with BEV followed by BEV and secondary cytoreductive surgery in platinum-sensitive, recurrent ovarian cancer, PPC and FTC. Over the next 3-4 years, the results of several BEV trials including GOG 213 will follow. ${ }^{5}$ Regardless of whether the results are positive or not, the pending problem currently faced is the identification of biomarkers that can be used to select patients for BEV. This will assist in the decision regarding the indication and best sched- ule for BEV therapy.

\section{Best chemotherapeutic regimen in recurrent ovarian cancer}

Platinum is the basis of treatment, and paclitaxel/carboplatin have emerged as a standard in a first-line setting and as a rechallenge for patients with platinum-sensitive recurrent ovarian cancer, ${ }^{10-13}$ even though the prognosis of ovarian cancer remains poor. Many different second-line regimens, as a single or a combination, have been being tested for their efficacy and toxicity in RCTs with the aim of improving the prognosis of recurrent ovarian cancer. The regimen that has shown at least non-inferior activity and has been approved by the US Food and Drug Administration (FDA) include platinum compounds, paclitaxel, pegylated liposomal doxorubicin (PLD), altretamine, and topotecan. $^{12,14-20}$

Among them, PLD has been demonstrated to be superior to topotecan/gemcitabine in trials in second-line settings. ${ }^{21-23}$ In 2010, there was notable progress in studies with PLD/trabectedin with various combinations in recurrent ovarian cancer. Caelyx in Platinum Sensitive Ovarian (CALYPSO) patients the largest phase III RCT in recurrent ovarian cancer, was designed to test the efficacy and safety of a combination of PLD $\left(30 \mathrm{mg} / \mathrm{m}^{2}\right)$ with carboplatin (AUC 5) every 4 weeks, compared to standard paclitaxel $\left(175 \mathrm{mg} / \mathrm{m}^{2}\right) /$ carboplatin (AUC 5) every 3 weeks for at least 6 cycles in patients with a platinum-sensitive recurrent ovarian cancer. ${ }^{24}$ The PFS for the PLD-carboplatin arm was superior to that of the paclitaxel/carboplatin arm (HR, 0.821; 95\% CI, 0.72 to 0.94; $\mathrm{p}=$ $0.005)$ with the median PFS being 11.3 vs. 9.4 months. The PLD-carboplatin was associated with less severe toxicity than paclitaxel/carboplatin: hair loss (7\% vs. $83.6 \%$; p $<0.001)$, grade 2 or higher neuropathy ( $4.9 \%$ vs. $26.9 \%$; $<<0.001)$, and carboplatin hypersensitivity reactions $(5.6 \%$ vs. $18.8 \%$; $p$ $<0.001)$. Therefore, PLD-carboplatin provides a more effective, less toxic alternative to the current standard for patients with platinum-sensitive recurrent ovarian cancer.

Systematic analysis of the peer-reviewed literature that compared PLD/carboplatin with gemcitabine/carboplatin for patients with platinum-sensitive recurrent ovarian cancer also reported a longer PFS and OS for the PLD/carboplatin regimen with better tolerability than gemcitabine/carboplatin. This suggests that PLD/carboplatin is a rational alternative to gemcitabine/carboplatin for the treatment of patients with platinum-sensitive recurrent ovarian cancer. ${ }^{25}$

Monk et al. ${ }^{20}$ performed another influential study of the PLD in recurrent ovarian cancer, OVA-301, in which the patients were randomized to PLD alone $\left(50 \mathrm{mg} / \mathrm{m}^{2}\right)$ every 4 weeks, or PLD $\left(30 \mathrm{mg} / \mathrm{m}^{2}\right)$ followed by trabectedin $\left(1.1 \mathrm{mg} / \mathrm{m}^{2}\right)$ every 3 weeks. The median PFS was 7.3 months with PLD/trabectedin vs. 5.8 months with PLD alone (HR, 0.79; 95\% CI, 0.65 to 0.96; $\mathrm{p}=0.0190$ ). The PFS and the overall response rates of PLD/trabectedin were superior to PLD alone, but only for platinum-sensitive patients, not for platinum-resistant patients. 
Although neutropenia was more common with PLD/trabectedin and the OS data was preliminary, this combination provided a new option for platinum-sensitive patients with recurrent ovarian cancer.

After OVA-301, subgroup analysis was performed in the partially platinum-sensitive (platinum-free interval [PFI], 6 to 12 months) subpopulation. ${ }^{26}$ Patients in the PLD/trabectedin arm received subsequent chemotherapy at a later time (median delay 2.5 months vs. PLD alone arm). A significantly prolonged OS from subsequent platinum was observed in this partially platinum-sensitive subset (HR, 0.63, $\mathrm{p}=0.0357$; median 13.3 vs. 9.8 months). In addition, Kaye et al. ${ }^{27}$ suggested that the enhanced survival benefits in the partially platinum-sensitive subset might be due to the extended PFI leading to a longer survival with subsequent platinum, which was also presented in the 13th IGCS biennial meeting.

Because the OS advantage has not been proven, the PLD/trabectedin may be an important option for patients with platinum-sensitive relapse who cannot tolerate platinum as a result of neuropathy or hypersensitivity. Otherwise platinumbased therapy should still be considered the treatment of choice in platinum-sensitive recurrent ovarian cancer. ${ }^{19}$

3. Neoadjuvant chemotherapy in advanced ovarian cancer After the preliminary data report of the first RCT directly addressing this issue at the 12th IGCS biennial meeting in 2008, the final analyses were published this year. ${ }^{28} \mathrm{~A}$ total of $670 \mathrm{pa}-$ tients with stage IIIc or IV were assigned randomly to primary debulking surgery followed by platinum-based chemotherapy or to neoadjuvant chemotherapy (NAC) followed by interval debulking. Optimal debulking (largest residual tumor $\leq 1$ $\mathrm{cm}$ ) was achieved after primary and interval debulking surgery in $41.6 \%$ and $80.6 \%$, respectively. The postoperative adverse effects and mortality were higher after primary debulking than after interval debulking. The OS and PFS were similar in both groups. Therefore, NAC followed by interval debulking may be a treatment option for patients with bulky stage IIIc or IV ovarian carcinoma. The authors also mentioned that a complete resection of all macroscopic disease (at primary debulking or interval surgery) was the strongest independent variable in predicting the OS.

Recently, there has been growing consensus that optimal cytoreduction should no longer be defined as a residual tumor $<1$ or $<0.5 \mathrm{~cm}$ but as a resection without a macroscopic residual tumor. ${ }^{29,30}$ However, aggressive cytoreduction is not always feasible. ${ }^{31}$ In addition, a significant decrease in the OS was noted in the trial by Vergote et al. ${ }^{29}$ during the first 3 months after randomization in patients undergoing primary debulking. This was most likely due to postoperative mortality and a delay in postoperative chemotherapy. These points that have prompted interest in NAC followed by interval debulking as a primary treatment in advanced ovarian cancer.

Although this topic was already covered at the 'Major Clinical Research Advances in Gynecologic Cancer' in 2008, there is a good reason to review it again because contrary to our expectations, the proven non-inferiority of NAC followed by interval debulking does not appear to bring about a significant change in the clinical practice of ovarian cancer patients with stage IIIc and IV. ${ }^{29,31}$ In an interesting questionnaire on NAC in advanced ovarian cancer targeting SGO members, ${ }^{32} 60 \%$ of respondents answered that they used NAC in less than $10 \%$ of their patients with advanced stage ovarian cancer. Most respondents (82\%) did not consider the available evidence sufficient to justify NAC followed by interval debulking. ${ }^{29}$ This uncertain reluctance to adopt NAC as a standard treatment created some controversy at the 13th IGCS biennial meeting.

Dr. Vergote (Belgium) and Dr. Hoskins (Canada) were on the pro side, whereas Dr. Chi (USA) and Dr. du Bois (Germany) had the alternative view. Dr. Chi mentioned the history of opposite results of trials from Europe and USA and continued to state that the different results might be caused by the different debulking rate and different efficacy of the chemotherapy regimen used. From this point of view, he suggested that the study by Vergote et al. ${ }^{29}$ is not enough to justify NAC, because there were several institutions where optimal debulking rates were far below average. However, there is no evidence that an increased optimal debulking rate would negate the beneficial effects of NAC. Furthermore, because optimal debulking rates of most institutions are likely to be in the range of $30.6 \%$ to $71.0 \%$ (the range of optimal debulking rate in Vergote trial), we can accept the conclusion favoring NAC.

It is important to determine the indication of NAC. The main predictive factors of debulking surgery resulting in no residual macroscopic tumor, such as co-morbidities, age, disease burden, location of metastatic sites, performance status, and stage, should be considered when deciding whether a patient is a candidate for primary debulking surgery or for NAC. ${ }^{29}$

\section{Dual tests might permit ovarian cancer screening}

The absence of both an effective screening method and early symptoms contributes to the poor prognosis of ovarian cancer. More than two thirds of ovarian cancers are diagnosed when the disease has progressed to stage III or IV..$^{33}$ The 5 -year survival rate is approximately $90 \%$ when ovarian cancer is detected and treated while it is still confined to the ovary (stage I), which is in contrast to the rate of approximately $33 \%$ when the disease is diagnosed at stage III or IV. ${ }^{34}$ This is why ovarian cancer is called the 'silent killer.'

Routine screening is not recommended by any professional groups, including US Preventive Services Task Force, American Cancer Society, American College of Obstetricians and Gynecologists, and National Comprehensive Cancer Network. ${ }^{35-37}$ It is not easy for investigators to develop a good screening test for ovarian cancer because it requires both high sensitivity and high specificity given the low prevalence of ovarian cancer, at least $75 \%$ sensitivity and $99.6 \%$ specificity to achieve a positive predictive value (PPV) of $10 \%$, which is the minimum PPV set 
by most epidemiologists to support a screening test. ${ }^{34}$

Of the two large RCTs that have completed the enrollment of patients, Prostate, Lung, Colon, and Ovarian (PLCO) Cancer Screening Trial, ${ }^{38}$ and the United Kingdom Collaborative Trial of Ovarian Cancer Screening (UKCTOCS), ${ }^{39}$ only the latter reported promising preliminary findings last year. In UKCTOCS, 202,638 postmenopausal women with an average risk for ovarian cancer were assigned randomly to undergo an annual pelvic examination (control group), annual transvaginal ultrasonography (TVS) (USG group), or annual measurement of the CA125 level (evaluated over time using the risk of ovarian cancer algorithm, ROCA) plus TVS in cases in which the CA-125 level was elevated (multimodality group) ${ }^{39}$ Surgery was performed less frequently in the multimodality group than in the USG group $(0.2 \%$ vs. $1.8 \%)$. Of the invasive cancers that were detected by screening in the two groups, $48 \%$ were stage I and II. Compared to the USG group, multimodality screening had a greater specificity (99.8\% vs. $98.2 \%)$ and higher PPV (35.1\% vs. $2.8 \%)(p<0.001)$. The final results are expected in 2015 . Lu et al. ${ }^{40}$ performed a single arm, prospective, multicenter screening study using the same ROCA in the US and presented the results at 2010 ASCO Annual Meeting (abstract 5003). A total of 3,238 participants basically underwent an annual CA-125 blood test. Based on the ROCA, they were triaged to the next annual CA-125 (low risk), repeat CA-125 in 3 months (intermediate risk), or TVS and referral to a gynecologic oncologist (high risk) who made the decision as to whether to proceed with surgery. The average annual rates of referral in the intermediate risk and high risk groups were $6.8 \%$ and $0.9 \%$, respectively. Eight women subsequently underwent surgery with 3 invasive cancers, 2 borderline and 3 benign tumors. The combined specificity of ROCA followed by TVS for referral to surgery was $99.7 \%$ and the PPV was $37.5 \%$. All 3 invasive cancers were in the early stages (2 Ic and $1 \mathrm{IIb})$. The authors concluded that ROCA followed by TVS is a feasible screening strategy with excellent specificity and PPV in US women with an average risk of ovarian cancer. The results are expected to be confirmed by UKCTOCS when the final report is released.

\section{Taking a step forward to the origin of ovarian cancer}

The early development of ovarian cancer is not completely understood. Most studies focused on serous adenocarcinoma, the most common histological type of ovarian carcinoma. On the other hand, rarer types, such as clear-cell and endometrioid, have attracted less attention despite their relative high incidence (accounting for $12 \%$ of cases in North America and even more in Japan), ${ }^{41}$ and refractoriness to standard platinum-based chemotherapy. ${ }^{42}$ The mechanisms of the transformation of endometriosis into clear cell carcinoma (CCC) and endometrioid carcinoma are still unknown, even though there is evidence suggesting that both CCC and endometrioid carcinoma are associated with endometriosis. ${ }^{43-45}$

This year, some part of the molecular genetic pathogenesis was unveiled by Wiegand et al. ${ }^{46}$ They found somatic mutations in ARID1A (the AT-rich interactive domain 1A [SWIlike] gene) through RNA sequencing of 18 CCC and a CCC cell line. ARID1A encodes BAF250a, which participates in the chromatin remodeling involved in the regulation of many cellular processes, such as differentiation, proliferation, DNA repair and tumor suppression. ${ }^{47}$ When they sequenced ARID1A in an additional 210 ovarian carcinomas and a second CCC cell line, $46 \%$ of patients with CCC and $30 \%$ of those with endometrioid carcinoma had somatic mutations in ARID1A, whereas no ARID1A mutations were found in any of the 76 high-grade serous carcinomas. Furthermore, immunohistochemical analysis in additional 455 ovarian carcinomas revealed that a loss of ARID1A expression was also specific to the subtype and the presence of mutations was strongly correlated with the loss of the BAF250a protein. Interestingly, ARID1A mutations and a loss of BAF250a expression were evident in the tumor and adjacent atypical endometriosis, but not in the distant endometriotic lesions in two patients. This suggests that a mutation is an early event in the neoplastic transformation from an endometriotic lesion to cancers.

Considering this study result as well as the nature of the somatic mutations in tumors as tumor suppressor genes, all tumor suppressor genes are mutated at a variety of positions throughout the coding region of the gene. This holds true for mutations in ARID1A, where ARID1A may function as a tumor suppressor gene.

Even if the clinical application is remote, the possibility that ARID1A can trigger a malignant transformation with a mutation and function as a tumor suppressor gene will have a substantial clinical impact. It may provide a clue not only to gene therapy, but also to a prevention strategy in CCC.

\section{Detection and prevention of human papillomavirus infection}

Human papillomavirus (HPV) has been a topic over the last two years in 'Major Clinical Research Advances in Gynecologic Cancer'. ${ }^{1,31}$ However, there are still many HPV-related issues to be explored.

The HPV test has higher sensitivity than a cytological test. Recent large RCTs demonstrated that the addition of a HPV test to the conventional or liquid-based cytology test alone to screen women for cervical cancer reduces the incidence of high-grade cervical intraepithelial neoplasia (CIN) at the subsequent screening. ${ }^{48-50}$ Therefore, the HPV test was incorporated into the established cervical cancer screening guidelines. ${ }^{51}$

In 2010, there were several confirmative RCTs that compared the efficacy of the HPV test in screening for cervical cancer with that of a cytological test. ${ }^{52,53}$ The study of Ronco et al. ${ }^{52}$ made up for the weak points of previous RCTs, ${ }^{48-50}$ showing a significant decrease in the incidence of invasive cancer and high-grade CIN during a second round of screening compared with the cytological test. Another RCT was a cohort 
study (PROHTECT) to assess the feasibility and efficacy of offering cervicovaginal lavage self sampling for high risk HPV testing to women who do not attend the regular screening program. Of the 7,404 women who submitted a self collected sample, 7,384 (99.8\%) had a valid result and 757 (10.3\%) were positive for high risk HPV. The study population also showed a higher incidence of CIN than the normal regular screened population ( $1.3 \%$ vs. $0.8 \%){ }^{54}$ This study suggested a good way of increasing the coverage in a screening program, which was as low as $65 \%$ of women in the Netherlands in 2005 , because the adjusted compliance rate in the self sampling group was significantly higher than in the control group (27.5\% vs. $16.6 \%$; $\mathrm{p}<0.001)$.

The final study we would like to mention in this issue was a pooled analysis of 2 RCTs regarding the risk of miscarriage with HPV vaccine. Last year, there was a combined analysis of five RCTs of pregnancy and infant outcomes in the clinical trials of a quadrivalent HPV vaccine. ${ }^{55}$ No significant differences were noted overall in the proportions of pregnancies resulting in live births, fetal loss, or spontaneous abortion between the vaccination and placebo groups. However, vaccination is not recommended during pregnancy. ${ }^{56}$ A pooled analysis this year confirmed the previous negative causal relationship. ${ }^{57}$ In this study, 26,130 women aged 15-25 were enrolled and randomized to 3 doses of bivalent vaccine or hepatitis A vaccine as the control. There was no significant increase in miscarriage in the women assigned to the HPV vaccine arm, even though there was a small increase in the risk of miscarriage ( $13.7 \%$ vs. $9.1 \% ; \mathrm{p}=0.033)$ in the subgroup of pregnancies conceived within the 3 months of vaccination. The authors attributed this finding to chance, but could not completely exclude the possibility of an increased risk among pregnancies conceived within 3 months of vaccination.

A cost-benefit analysis of the HPV screening test should be followed to minimize the costs related to the increased referral to a colposcopy and overdiagnosis of regressive lesions in the young age group.

\section{Laparoscopy and laparotomy in endometrial cancer staging operation}

Although this topic has not been covered at the last two December issues, the minimal invasive surgical approaches to staging women with endometrial cancer began as early as in the 1990s. ${ }^{58-61}$ Based on these studies, GOG conducted a RCT (GOG 2222, LAP2) that compared a laparotomy with laparoscopy in the surgical staging of endometrial cancer and reported some of the results last year. ${ }^{62,63}$ This study revealed that laparoscopic comprehensive surgical staging of endometrial cancer could result in less pain, faster recovery, fewer postoperative complications, and a shorter hospital stay than laparotomy with similar rates of intraoperative complications and the ability to identify metastatic disease. In addition, they reported a significantly better quality of life (QOL) across many parameters in the laparoscopy arm at 6 weeks after surgery. However, the significant difference did not last beyond 6 months except for the better body image in laparoscopy patients. The survival results will be reported when the data is established.

In 2010, there were two RCTs that confirmed the previous study results. In 2-stage RCT, the LACE trial, of which the primary objectives of each stage were the QOL and disease-free survival (DFS), the QOL results of stage 1 were reported. ${ }^{64}$ In the QOL substudy, 332 pathologic stage I patients were included, 142 in the total abdominal hysterectomy (TAH) group and 190 in the total laparoscopic hysterectomy (TLH) group. Patients in the TLH group showed greater QOL improvements from surgery at both the early (up to 4 weeks) and late (up to 6 months) postoperative recovery periods. Compared to the LAP2 trial, in which the QOL difference favoring a laparoscopy was significant only before 6 months after surgery, a consistent QOL difference was observed in the LACE trial. They suggested three possible explanations. First, the LAP2 trial required a full pelvic and aortic lymph node dissection (LND) in all patients, which resulted in a much higher conversion rate to a laparotomy than the LACE trial $(25.8 \%$ vs. $2.4 \%$ ). Patients who had received LND had a significantly lower functional wellbeing and functional assessment of the cancer therapy-general (FACT-G) scores at early recovery than those who did not. Furthermore, $52 \%$ of the total patients with fewer patients in the TLH group than TAH group underwent a pelvic or aortic LND in the LACE trial ( $67.6 \%$ vs. $40.5 \%$ ). Second, the LACE trial aimed to ensure that all surgeons were beyond their individual learning curves. Third, all procedures in the LACE trial were completed totally laparoscopically, whereas most procedures in the LAP2 trial were a laparoscopic-assisted vaginal hysterectomy (LAVH).

Another RCT published in 2010 compared the safety of TAH versus TLH. ${ }^{65}$ This study was performed with 283 patients with stage I endometrioid adenocarcinoma or complex atypical hyperplasia. They concluded that there was no evidence of a lower rate of major complications with TLH vs. TAH because of the low power for proving equivalence. However, they suggested a benefit for TLH over TAH because of the shorter hospital stay, less pain after surgery, and faster return to daily activities, which was in agreement with LAP2.

Regarding the safety and QOL, laparoscopic approaches are comparable to, or even better than a conventional laparotomy in the surgical staging of endometrial cancer. However, the physician's preference, conventions of the individual institutions, and surgeon experience are important factors because the survival results have not been reported.

\section{Internal radiation effectively reduces local recurrence of some endometrial cancers: PORTEC-2 trial}

PORTEC-1 and GOG 99 showed that pelvic external beam radiotherapy (EBRT) significantly reduced the rate of locoregional recurrence without an OS improvement in patients with high-intermediate risk (HIR) factors: 1) grade 2 or 3 , 
presence of lymphovascular invasion, and outer third myometrial invasion; 2) age 50 or more with any two of the risk factors listed above; or 3) age at least 70 with any one risk factor listed above. ${ }^{66-68}$ Because approximately $75 \%$ of recurrences in the control groups were vaginal recurrences in both trials, the PORTEC group commenced the subsequent trial, PORTEC-2, and published the final results this year. ${ }^{69}$

The PORTEC-2 trial compared the efficacy and toxicity of EBRT and vaginal brachytherapy (VBT) for endometrial cancer of HIR. After TAH with a bilateral salpingo-oophorectomy with the removal of clinically suspicious pelvic or para-aortic lymph nodes, 427 patients with HIR factors were assigned randomly to either the EBRT $(n=214)$ or VBT $(n=213)$. The primary endpoint was vaginal recurrence. At a median follow-up of 45 months, they estimated the 5-year data (EBRT vs. VBT) for vaginal recurrence ( $1.6 \%$ vs. $1.8 \%$; $\mathrm{p}=0.74$ ), pelvic recurrence $(0.5 \%$ vs. $3.8 \%$; $\mathrm{p}=0.02)$, and distant metastases $(5.7 \%$ vs. $8.3 \%$; $\mathrm{p}=0.46)$. Although the OS and DFS were similar in the two groups, the rates of acute grade 1-2 gastrointestinal toxicity at the completion of radiotherapy were significantly lower in the VBT group than in the EBRT group (12.6\% vs. 53.8\%).69 Therefore, they concluded that VBT should be the adjuvant treatment of choice for patients with an endometrial carcinoma of HIR.

While PORTEC-2 showed that VBT was as effective as EBRT in ensuring local control with less toxicity, endometrial cancer with HIR was likely to metastasize to distant sites, resulting in lower survival rates. This drove investigators to incorporate chemotherapy into RCTs of adjuvant treatments of endometrial cancer with HIR. An ongoing trial, PORTEC-3, is comparing concurrent chemoradiation (EBRT with 2 cycles of cisplatin in weeks 1 and 4 ) and adjuvant chemotherapy (4 cycles of carboplatin and paclitaxel at 3-week intervals) with pelvic radiation alone in high risk and advanced stage endometrial carcinoma. Another ongoing trial, GOG 249, is a phase III trial of EBRT versus VBT followed by paclitaxel/carboplatin in patients with a high risk of early stage endometrial carcinoma. More knowledge of the strategies that lead to better survival of endometrial cancer patients is expected through these trials.

\section{Extensive lymph node removal in endometrial cancer} The extent of LND was already discussed in 'Major Clinical Research Advances in Gynecologic Cancer 2008, ${ }^{31}$ Para-aortic lymph nodes (PALNs) at least up to the renal vessels level were suggested to be an adequate extent of LND. Although two large RCTs failed to show any therapeutic benefits of pelvic LND, ${ }^{70,71}$ the therapeutic value of LND in endometrial cancer is still controversial because of the limitations of RCTs, such as short follow-up period, low LN harvest number and exclusion of para-aortic LND. ${ }^{72-74}$

A large retrospective cohort study (SEPAL study) examined the survival effect of para-aortic LND in endometrial cancer this year. ${ }^{74}$ Of 671 patients, 325 and 346 were treated with pelvic LND and combined pelvic and para-aortic LND, respectively. The primary outcome, OS, was shown to be longer in the pelvic and para-aortic LND group than in the pelvic LND group (HR, 0.53; 95\% CI, 0.38 to $0.76 ; \mathrm{p}=0.0005$ ). However, this association was established only in patients with HIR factors $(p=0.0009)$, not in those with low risk factors. Combined pelvic and para-aortic LND added a $10.6 \%$ increase in the 5year OS compared to pelvic LND in HIR patients. Multivariate analysis showed that in addition to age, tumor type and LN metastasis, the type of LND was independently related to survival. In other words, combined pelvic and para-aortic LND was associated with significantly lower mortality than pelvic LND alone.

The rationale of para-aortic LND in endometrial cancer can be found in the literature. More than half of patients with pelvic $\mathrm{LN}$ metastasis have a PALN metastasis, and $10 \%$ of LN metastases occur exclusively in the para-aortic region. ${ }^{75,76}$ The para-aortic region also has been shown to be an important site of sentinel nodes in endometrial cancer, with $47 \%$ of paraaortic sentinel nodes and $77 \%$ of all PALN metastasis being located above the inferior mesenteric artery. ${ }^{75,77}$

The SEPAL study was not a prospective RCT. However, it compensated for the main weakness of ASTEC and BenedettiPanici's trial, i.e., the exclusion of para-aortic LND from the procedure of LND. To change the practice, the conclusion of the SEPAL study, i.e., a combination of pelvic and para-aortic LND can significantly improve the survival in patients with a HIR of recurrence, should be confirmed in a prospective RCT.

\section{Geriatric oncology}

Although there was no landmark study in geriatric oncology in 2010, there is a rapidly growing interest in this area due mainly to the increasing life expectancy, and the increasing risk of cancer with age. The proportion of elderly people (older than 65) will be between 10 and $30 \%$ in most countries, which means more than 1 billion worldwide. Furthermore, a quarter to a third are expected to develop cancer in some form, i.e., 250-300 million people. ${ }^{78}$

Why is it important to focus on geriatric oncology separate from general oncology? What is the problem with elderly cancer patients? Older people are more vulnerable or frail, and have higher prevalence of comorbidity. In addition, they exhibit variable pharmacokinetics/pharmacodynamics of cancer drugs, which can result in high rate of toxicity, a decrease in the functional status and a likelihood of developing second cancers. ${ }^{78,79}$ This often results in the under-treatment older female ovarian cancer patients. ${ }^{80}$ Older women with ovarian cancer are likely to undergo complete debulking surgery less frequently and receive adjuvant chemotherapy less frequently than their younger counterparts, which partly accounts for increased disease-specific mortality in older patients. ${ }^{81-84}$ Therefore, there is a good reason to select the patients who can endure the toxicity of standard chemotherapy as well as stressful extensive surgery. Accordingly, considerable effort has been placed into the devel- 
opment of geriatric assessment tools these days.

At the 35th ESMO annual congress, there was an interim analysis that evaluated the Groningen Frailty Index (GFI), a 15-item questionnaire, as a short screening tool to identify patients in need of a comprehensive geriatric assessment (CGA) because the CGA was a time consuming procedure. ${ }^{85}$ The GFI is a useful screening instrument for identifying vulnerable patients according to the CGA. A two step approach to the initial evaluation is becoming a paradigm of choice. ${ }^{78}$

At this year's ASCO meeting, two scores for predicting the toxicity from chemotherapy were presented. The first one, the CRASH score (chemotherapy risk assessment score for high age patients), which comprised of grade 4 hematologic and grade 3-4 non-hematologic toxicity, was found to offer a validated, clinically applicable mean of predicting significant differences in the risk of severe toxicity. ${ }^{86}$ The second score, which was designed by Hurria et al., developed a risk stratification scheme for grade 3-5 toxicity based on a number of risk factors. ${ }^{87}$ The risk factors for grade 3-5 toxicity included age $\geq 73$, cancer type (gastrointestinal or genitourinary), standard dose, multiple chemotherapeutic agents, falls in the last 6 months, assistance with instrumental activities and decreased social activity. The percentage incidence of grade 3-5 toxicity for $1,2,3,4,5,6$, and 7 risk factors was $23 \%, 36 \%$, $50 \%, 60 \%, 83 \%, 90 \%$, and $100 \%$, respectively. However, integration of these instruments as decision making tools in geriatric oncology is needed. ${ }^{78}$

Apart from the development of geriatric assessment tools, more effort to include older patients in prospective RCTs is needed to establish a standard therapy for older patients.

\section{Chemotherapy in uterine carcinosarcoma}

A recent study revealed that carcinosarcoma (CS), which was formerly known as a malignant mixed mullerian tumor, might represent metaplastic carcinomas with a sarcomatous component being a dedifferentiation of the carcinomatous component. ${ }^{88}$ Based on this histological background of an epithelial origin and the common tumor biological behavior, CS and endometrial adenocarcinoma share a similar FIGO staging system. ${ }^{89,90}$ However, CSs are definitely more aggressive and fatal in a vast majority of cases than endometrial adenocarcinomas. The five-year OS is approximately $50 \%$, even in stage I CSs, which in contrast to the approximately $80 \%$ or better in stage I endometrial adenocarcinomas. ${ }^{89}$ Despite the poor prognosis, there have been relatively few trials aimed at developing more effective chemotherapeutic regimens due mainly to the rarity of CSs. ${ }^{91}$

Up to a few decades ago, ifosfamide $\left(32 \%,{ }^{92} 36 \%^{93}\right)$, etoposide $\left(7 \%^{94}\right)$, and doxorubicin $\left(10 \%{ }^{95}\right)$ were the most active agents in patients with CSs. Since the moderate activity of cisplatin (18\%) and paclitaxel (18\%), which have been used primarily for epithelial tumors, such as epithelial ovarian carcinomas or endometrial adenocarcinomas, was reported recently, ${ }^{96,97}$ investigators have been initiating new trials to evaluate the effi- cacy and toxicity of those agents in a combination setting in CSs. Paclitaxel combined with ifosfamide significantly improved the OS in CS compared to ifosfamide alone (13.5 months vs. 8.4 months; HR, 0.69; $95 \% \mathrm{CI}, 0.49$ to $0.97 ; \mathrm{p}=0.03$ ) and the toxicities were as expected and manageable. ${ }^{91}$ The authors highlighted the continuing necessity of new active agents considering the poor OS.

In accordance with this necessity, another combination of paclitaxel and carboplatin was evaluated in a phase II trial by the GOG this year. ${ }^{98}$ Fifty-five patients were enrolled in the study, and 46 were evaluated for the antitumor activity and toxicity. This regimen was well tolerated with $59 \%$ of patients completing six or more chemotherapy cycles. The total overall response rate was $54 \%$ (95\% CI, 37 to $67 \%)$. Based on these promising results, the GOG is now proceeding with a phase III non-inferiority trial that is comparing paclitaxel/carboplatin with paclitaxel/ifosfamide in CS patients with stage I-IV, recurrent or persistent, measurable or nonmeasurable disease. The results of this trial are expected to provide a more effective chemotherapy strategy for CS.

\section{CONCLUSION}

RCT is the best way of changing the major practice guidelines. However, it is time consuming in that it generally takes more than a decade for a new concept to become a reality in practice, particularly when the trial results are unsatisfactory. More promising results of RCTs are expected regarding BEV. However, it is important to wait for the final report and continue to work to maximizing the benefit.

On the other hand, there are many other areas in gynecologic oncology that remain to be solved, such as the origin of cancer and geriatric oncology. More studies in the future should focus on these areas as well as various patient management strategies.

\section{CONFLICT OF INTEREST}

No potential conflict of interest relevant to this article was reported.

\section{REFERENCES}

1. Kim K, Ryu SY. Major clinical research advances in gynecologic cancer 2009. J Gynecol Oncol 2009; 20: 203-9.

2. Burger RA, Sill MW, Monk BJ, Greer BE, Sorosky JI. Phase II trial of bevacizumab in persistent or recurrent epithelial ovarian cancer or primary peritoneal cancer: a Gynecologic Oncology Group Study. J Clin Oncol 2007; 25: 5165-71.

3. Cannistra SA, Matulonis UA, Penson RT, Hambleton J, Dupont $\mathrm{J}$, Mackey $\mathrm{H}$, et al. Phase II study of bevacizumab in patients with platinum-resistant ovarian cancer or peritoneal serous cancer. J Clin Oncol 2007; 25: 5180-6.

4. Garcia AA, Hirte H, Fleming G, Yang D, Tsao-Wei DD, Roman $\mathrm{L}$, et al. Phase II clinical trial of bevacizumab and low-dose metronomic oral cyclophosphamide in recurrent ovarian cancer: a trial of the California, Chicago, and Princess Margaret Hospital 
phase II consortia. J Clin Oncol 2008; 26: 76-82.

5. Ledermann JA, Raja FA. Targeted trials in ovarian cancer. Gynecol Oncol 2010; 119: 151-6.

6. Burger RA, Brady MF, Bookman MA, Walker JL, Homesley HD, Fowler J, et al. Phase III trial of bevacizumab (BEV) in the primary treatment of advanced epithelial ovarian cancer (EOC), primary peritoneal cancer (PPC), or fallopian tube cancer (FTC): a Gynecologic Oncology Group study. 2010 ASCO Annual Meeting, Abstract LBA1.

7. Perren T, Swart AM, Pfisterer J, Ledermann J, Lortholary A, Kristensen G, et al. ICON7: a phase III randomised gynaecologic cancer intergroup trial of concurrent bevacizumab and chemotherapy followed by maintenance bevacizumab, versus chemotherapy alone in women with newly diagnosed epithelial ovarian (EOC), primary peritoneal (PPC) or fallopian tube cancer (FTC). ESMO 2010, Abstract LBA4.

8. Han ES, Monk BJ. What is the risk of bowel perforation associated with bevacizumab therapy in ovarian cancer? Gynecol Oncol 2007; 105: 3-6.

9. Avastin full prescribing information: inications [Internet]. South San Francisco: Genentech, Inc.; 2009 [cited 2010 Nov 14]. Available from: http://www.gene.com/gene/products/information/ pdf/avastin-prescribing.pdf.

10. Berek JS, Bertelsen K, du Bois A, Brady MF, Carmichael J, Eisenhauer EA, et al. Advanced epithelial ovarian cancer: 1998 consensus statements. Ann Oncol 1999; 10 Suppl 1: 87-92.

11. Orlando M, Costanzo MV, Chacon RD, Tajer CD. Randomized trials of combination chemotherapy (combo) versus monotherapy (mono) in relapsed ovarian carcinoma (ROC): a meta-analysis of published data. 2007 ASCO Annual Meeting, Abstract 5524.

12. Parmar MK, Ledermann JA, Colombo N, du Bois A, Delaloye JF, Kristensen GB, et al. Paclitaxel plus platinum-based chemotherapy versus conventional platinum-based chemotherapy in women with relapsed ovarian cancer: the ICON4/AGO-OVAR2.2 trial. Lancet 2003; 361: 2099-106.

13. Pfisterer J, Ledermann JA. Management of platinum-sensitive recurrent ovarian cancer. Semin Oncol 2006; 33(2 Suppl 6): S12-6.

14. Pfisterer J, Plante M, Vergote I, du Bois A, Hirte H, Lacave AJ, et al. Gemcitabine plus carboplatin compared with carboplatin in patients with platinum-sensitive recurrent ovarian cancer: an intergroup trial of the AGO-OVAR, the NCIC CTG, and the EORTC GCG. J Clin Oncol 2006; 24: 4699-707.

15. Murgia V, Sorio R, Griso C, Caffo O, Arcuri C, Ferro A, et al. Multicenter phase 2 study of combined gemcitabine and epirubicin as second-line treatment for patients with advanced ovarian cancer. Int J Gynecol Cancer 2010; 20: 953-7.

16. Kim HS, Park NH, Kang S, Seo SS, Chung HH, Kim JW, et al. Comparison of the efficacy between topotecan- and belotecan-, a new camptothecin analog, based chemotherapies for recurrent epithelial ovarian cancer: a single institutional experience. J Obstet Gynaecol Res 2010; 36: 86-93.

17. Nam EJ, Kim JW, Kim JH, Kim S, Kim SW, Jang SY, et al. Efficacy and toxicity of belotecan with and without cisplatin in patients with recurrent ovarian cancer. Am J Clin Oncol 2010; 33: 233-7.

18. Kim YM, Lee SW, Kim DY, Kim JH, Nam JH, Kim YT. The efficacy and toxicity of belotecan (CKD-602), a camptothericin analogue topoisomerase I inhibitor, in patients with recurrent or refractory epithelial ovarian cancer. J Chemother 2010; 22: 197200.

19. Cannistra SA. Evaluating new regimens in recurrent ovarian cancer: how much evidence is good enough? J Clin Oncol 2010; 28: 3101-3.

20. Monk BJ, Herzog TJ, Kaye SB, Krasner CN, Vermorken JB, Muggia FM, et al. Trabectedin plus pegylated liposomal Doxorubicin in re- current ovarian cancer. J Clin Oncol 2010; 28: 3107-14.

21. Gordon AN, Fleagle JT, Guthrie D, Parkin DE, Gore ME, Lacave AJ. Recurrent epithelial ovarian carcinoma: a randomized phase III study of pegylated liposomal doxorubicin versus topotecan. J Clin Oncol 2001; 19: 3312-22.

22. Gordon AN, Tonda M, Sun S, Rackoff W; Doxil Study 30-49 Investigators. Long-term survival advantage for women treated with pegylated liposomal doxorubicin compared with topotecan in a phase 3 randomized study of recurrent and refractory epithelial ovarian cancer. Gynecol Oncol 2004; 95: 1-8.

23. Ferrandina G, Ludovisi M, Lorusso D, Pignata S, Breda E, Savarese A, et al. Phase III trial of gemcitabine compared with pegylated liposomal doxorubicin in progressive or recurrent ovarian cancer. J Clin Oncol 2008; 26: 890-6.

24. Pujade-Lauraine E, Wagner U, Aavall-Lundqvist E, Gebski V, Heywood M, Vasey PA, et al. Pegylated liposomal Doxorubicin and Carboplatin compared with Paclitaxel and Carboplatin for patients with platinum-sensitive ovarian cancer in late relapse. J Clin Oncol 2010; 28: 3323-9.

25. Holloway RW, Grendys EC, Lefebvre P, Vekeman F, McMeekin S. Tolerability, efficacy, and safety of pegylated liposomal Doxorubicin in combination with Carboplatin versus gemcitabine-Carboplatin for the treatment of platinum-sensitive recurrent ovarian cancer: a systematic review. Oncologist 2010; 15: 1073-82.

26. Poveda A, Vergote I, Tjulandin S, Kong B, Roy M, Chan S, et al. Trabectedin plus pegylated liposomal doxorubicin in relapsed ovarian cancer: outcomes in the partially platinum-sensitive (platinum-free interval 6-12 months) subpopulation of OVA-301 phase III randomized trial. Ann Oncol 2010 Jul 19 [Epub]. DOI: 10.1093/annonc/mdq352.

27. Kaye SB, Colombo N, Monk BJ, Tjulandin S, Kong B, Roy M, et al. Trabectedin plus pegylated liposomal doxorubicin in relapsed ovarian cancer delays third-line chemotherapy and prolongs the platinum-free interval. Ann Oncol 2010 Jul 19 [Epub]. DOI:10. 1093/annonc/mdq353.

28. Vergote I, Trope CG, Amant F, Kristensen GB, Ehlen T, Johnson $\mathrm{N}$, et al. Neoadjuvant chemotherapy or primary surgery in stage IIIC or IV ovarian cancer. N Engl J Med 2010; 363: 943-53.

29. Vergote I, Amant F, Leunen K. Neoadjuvant chemotherapy in advanced ovarian cancer: what kind of evidence is needed to convince US gynaecological oncologists? Gynecol Oncol 2010; 119: 1-2.

30. Chi DS, Eisenhauer EL, Lang J, Huh J, Haddad L, Abu-Rustum $\mathrm{NR}$, et al. What is the optimal goal of primary cytoreductive surgery for bulky stage IIIC epithelial ovarian carcinoma (EOC)? Gynecol Oncol 2006; 103: 559-64.

31. Kim K, Choi SC, Ryu SY, Kim JW, Kang SB. Major clinical research advances in gynecologic cancer 2008. J Gynecol Oncol 2008; 19: 209-17.

32. Dewdney SB, Rimel BJ, Reinhart AJ, Kizer NT, Brooks RA, Massad LS, et al. The role of neoadjuvant chemotherapy in the management of patients with advanced stage ovarian cancer: survey results from members of the Society of Gynecologic Oncologists. Gynecol Oncol 2010; 119: 18-21.

33. Heintz AP, Odicino F, Maisonneuve P, Quinn MA, Benedet JL, Creasman WT, et al. Carcinoma of the ovary: FIGO 6th annual report on the results of treatment in gynecological cancer. Int J Gynaecol Obstet 2006; 95 Suppl 1: S161-92.

34. Clarke-Pearson DL. Clinical practice: screening for ovarian cancer. N Engl J Med 2009; 361: 170-7.

35. Clinical practice guidelines in oncology. Genetic/familial highrisk assessment: breast and ovarian V.I.2010 [Internet]. Fort Washington: National Comprehensive Cancer Network; [cited 2010 Nov 14]. Available from: http://www.nccn.org/professionals/ physician gls/PDF/genetics_screening.pdf. 
36. U.S. Preventive Services Task Force. Screening for ovarian cancer: recommendation statement. U.S. Preventive Services Task Force. Am Fam Physician 2005; 71: 759-62.

37. American College of Obstetricians and Gynecologists, Committee on Gynecologic Practice. ACOG committee opinion: Von Willebrand's disease in gynecologic practice. Int J Gynaecol Obstet 2002; 76: 336-7.

38. Partridge E, Kreimer AR, Greenlee RT, Williams C, Xu JL, Church TR, et al. Results from four rounds of ovarian cancer screening in a randomized trial. Obstet Gynecol 2009; 113: 775-82.

39. Menon U, Gentry-Maharaj A, Hallett R, Ryan A, Burnell M, Sharma A, et al. Sensitivity and specificity of multimodal and ultrasound screening for ovarian cancer, and stage distribution of detected cancers: results of the prevalence screen of the UK Collaborative Trial of Ovarian Cancer Screening (UKCTOCS). Lancet Oncol 2009; 10: 327-40.

40. Lu KH, Skates S, Bevers TB, Newland W, Moore RG, Leeds L, et al. A prospective U.S. ovarian cancer screening study using the risk of ovarian cancer algorithm (ROCA). 2010 ASCO Annual Meeting, Abstract 5003.

41. Itamochi H, Kigawa J, Terakawa N. Mechanisms of chemoresistance and poor prognosis in ovarian clear cell carcinoma. Cancer Sci 2008; 99: 653-8.

42. Jones S, Wang TL, Shih Ie M, Mao TL, Nakayama K, Roden R, et al. Frequent mutations of chromatin remodeling gene ARID1A in ovarian clear cell carcinoma. Science 2010; 330: 228-31.

43. Veras E, Mao TL, Ayhan A, Ueda S, Lai H, Hayran M, et al. Cystic and adenofibromatous clear cell carcinomas of the ovary. Distinctive tumors that differ in their pathogenesis and behavior: a clinicopathologic analysis of 122 cases. Am J Surg Pathol 2009; 33: 844-53.

44. Vigano P, Somigliana E, Chiodo I, Abbiati A, Vercellini P. Molecular mechanisms and biological plausibility underlying the malignant transformation of endometriosis: a critical analysis. Hum Reprod Update 2006; 12: 77-89.

45. Ness RB. Endometriosis and ovarian cancer: thoughts on shared pathophysiology. Am J Obstet Gynecol 2003; 189: 280-94.

46. Wiegand KC, Shah SP, Al-Agha OM, Zhao Y, Tse K, Zeng T, et al. ARID1A mutations in endometriosis-associated ovarian carcinomas. N Engl J Med 2010; 363: 1532-43.

47. Reisman D, Glaros S, Thompson EA. The SWI/SNF complex and cancer. Oncogene 2009; 28: 1653-68.

48. Naucler P, Ryd W, Tornberg S, Strand A, Wadell G, Elfgren K, et al. Human papillomavirus and Papanicolaou tests to screen for cervical cancer. N Engl J Med 2007; 357: 1589-97.

49. Bulkmans NW, Berkhof J, Rozendaal L, van Kemenade FJ, Boeke AJ, Bulk S, et al. Human papillomavirus DNA testing for the detection of cervical intraepithelial neoplasia grade 3 and cancer: 5 -year follow-up of a randomised controlled implementation trial. Lancet 2007; 370: 1764-72.

50. Kitchener HC, Almonte M, Thomson C, Wheeler P, Sargent A, Stoykova B, et al. HPV testing in combination with liquid-based cytology in primary cervical screening (ARTISTIC): a randomised controlled trial. Lancet Oncol 2009; 10: 672-82.

51. Clinical practice guidelines in oncology. Cervical cancer screening V.I.2011 [Internet]. Fort Washington: National Comprehensive Cancer Network; [cited 2010 Nov 17]. Available from: http:// www.nccn.org/professionals/physician_gls/PDF/cervical_ screening.pdf.

52. Ronco G, Giorgi-Rossi P, Carozzi F, Confortini M, Dalla Palma P, Del Mistro A, et al. Efficacy of human papillomavirus testing for the detection of invasive cervical cancers and cervical intraepithelial neoplasia: a randomised controlled trial. Lancet Oncol
2010; 11: 249-57.

53. Anttila A, Kotaniemi-Talonen L, Leinonen M, Hakama M, Laurila P, Tarkkanen J, et al. Rate of cervical cancer, severe intraepithelial neoplasia, and adenocarcinoma in situ in primary HPV DNA screening with cytology triage: randomised study within organised screening programme. BMJ 2010; 340: c1804.

54. Gok M, Heideman DA, van Kemenade FJ, Berkhof J, Rozendaal L, Spruyt JW, et al. HPV testing on self collected cervicovaginal lavage specimens as screening method for women who do not attend cervical screening: cohort study. BMJ 2010; 340: c1040.

55. Garland SM, Ault KA, Gall SA, Paavonen J, Sings HL, Ciprero $\mathrm{KL}$, et al. Pregnancy and infant outcomes in the clinical trials of a human papillomavirus type $6 / 11 / 16 / 18$ vaccine: a combined analysis of five randomized controlled trials. Obstet Gynecol 2009; 114: 1179-88.

56. Markowitz LE, Dunne EF, Saraiya M, Lawson HW, Chesson H, Unger ER, et al. Quadrivalent human papillomavirus vaccine: recommendations of the Advisory Committee on Immunization Practices (ACIP). MMWR Recomm Rep 2007; 56: 1-24.

57. Wacholder S, Chen BE, Wilcox A, Macones G, Gonzalez P, Befano $B$, et al. Risk of miscarriage with bivalent vaccine against human papillomavirus (HPV) types 16 and 18: pooled analysis of two randomised controlled trials. BMJ 2010; 340: c712.

58. Dargent D. Laparoscopic surgery and gynecologic cancer. Curr Opin Obstet Gynecol 1993; 5: 294-300.

59. Querleu D, Leblanc E, Castelain B. Laparoscopic pelvic lymphadenectomy in the staging of early carcinoma of the cervix. Am J Obstet Gynecol 1991; 164: 579-81.

60. Childers JM, Spirtos NM, Brainard P, Surwit EA. Laparoscopic staging of the patient with incompletely staged early adenocarcinoma of the endometrium. Obstet Gynecol 1994; 83: 597-600.

61. Spirtos NM, Schlaerth JB, Spirtos TW, Schlaerth AC, Indman PD, Kimball RE. Laparoscopic bilateral pelvic and paraaortic lymph node sampling: an evolving technique. Am J Obstet Gynecol 1995; 173: 105-11.

62. Walker JL, Piedmonte MR, Spirtos NM, Eisenkop SM, Schlaerth JB, Mannel RS, et al. Laparoscopy compared with laparotomy for comprehensive surgical staging of uterine cancer: Gynecologic Oncology Group Study LAP2. J Clin Oncol 2009; 27: 5331-6.

63. Kornblith AB, Huang HQ, Walker JL, Spirtos NM, Rotmensch J, Cella D. Quality of life of patients with endometrial cancer undergoing laparoscopic international federation of gynecology and obstetrics staging compared with laparotomy: a Gynecologic Oncology Group study. J Clin Oncol 2009; 27: 5337-42.

64. Janda M, Gebski V, Brand A, Hogg R, Jobling TW, Land R, et al. Quality of life after total laparoscopic hysterectomy versus total abdominal hysterectomy for stage I endometrial cancer (LACE): a randomised trial. Lancet Oncol 2010; 11: 772-80.

65. Mourits MJ, Bijen CB, Arts HJ, ter Brugge HG, van der Sijde R, Paulsen L, et al. Safety of laparoscopy versus laparotomy in early-stage endometrial cancer: a randomised trial. Lancet Oncol 2010; 11: 763-71.

66. Creutzberg CL, van Putten WL, Koper PC, Lybeert ML, Jobsen JJ, Warlam-Rodenhuis CC, et al. Surgery and postoperative radiotherapy versus surgery alone for patients with stage- 1 endometrial carcinoma: multicentre randomised trial. PORTEC Study Group. Post Operative Radiation Therapy in Endometrial Carcinoma. Lancet 2000; 355: 1404-11.

67. Scholten AN, van Putten WL, Beerman H, Smit VT, Koper PC, Lybeert ML, et al. Postoperative radiotherapy for Stage 1 endometrial carcinoma: long-term outcome of the randomized PORTEC trial with central pathology review. Int J Radiat Oncol Biol Phys 2005; 63: 834-8.

68. Keys HM, Roberts JA, Brunetto VL, Zaino RJ, Spirtos NM, Bloss 
JD, et al. A phase III trial of surgery with or without adjunctive external pelvic radiation therapy in intermediate risk endometrial adenocarcinoma: a Gynecologic Oncology Group study. Gynecol Oncol 2004; 92: 744-51.

69. Nout RA, Smit VT, Putter H, Jurgenliemk-Schulz IM, Jobsen JJ, Lutgens LC, et al. Vaginal brachytherapy versus pelvic external beam radiotherapy for patients with endometrial cancer of high-intermediate risk (PORTEC-2): an open-label, non-inferiority, randomised trial. Lancet 2010; 375: 816-23.

70. ASTEC Study Group, Kitchener H, Swart AM, Qian Q, Amos C, Parmar MK. Efficacy of systematic pelvic lymphadenectomy in endometrial cancer (MRC ASTEC trial): a randomised study. Lancet 2009; 373: 125-36.

71. Benedetti Panici P, Basile S, Maneschi F, Alberto Lissoni A, Signorelli M, Scambia G, et al. Systematic pelvic lymphadenectomy vs. no lymphadenectomy in early-stage endometrial carcinoma: randomized clinical trial. J Natl Cancer Inst 2008; 100: 1707-16.

72. Yaegashi N, Ito K, Niikura H. Lymphadenectomy for endometrial cancer: is paraaortic lymphadenectomy necessary? Int $\mathrm{J}$ Clin Oncol 2007; 12: 176-80.

73. Frederick PJ, Straughn JM Jr. The role of comprehensive surgical staging in patients with endometrial cancer. Cancer Control 2009; 16: 23-9.

74. Todo Y, Kato H, Kaneuchi M, Watari H, Takeda M, Sakuragi N. Survival effect of para-aortic lymphadenectomy in endometrial cancer (SEPAL study): a retrospective cohort analysis. Lancet 2010; 375: 1165-72.

75. Mariani A, Dowdy SC, Cliby WA, Gostout BS, Jones MB, Wilson TO, et al. Prospective assessment of lymphatic dissemination in endometrial cancer: a paradigm shift in surgical staging. Gynecol Oncol 2008; 109: 11-8.

76. Yokoyama Y, Maruyama H, Sato S, Saito Y. Indispensability of pelvic and paraaortic lymphadenectomy in endometrial cancers. Gynecol Oncol 1997; 64: 411-7.

77. Niikura H, Okamura C, Utsunomiya H, Yoshinaga K, Akahira J, Ito $\mathrm{K}$, et al. Sentinel lymph node detection in patients with endometrial cancer. Gynecol Oncol 2004; 92: 669-74.

78. Extermann M. Geriatric oncology: an overview of progresses and challenges. Cancer Res Treat 2010; 42: 61-8.

79. Smorenburg $\mathrm{CH}$, ten Tije AJ, Verweij J, Bontenbal M, Mross K, van Zomeren DM, et al. Altered clearance of unbound paclitaxel in elderly patients with metastatic breast cancer. Eur J Cancer 2003; 39: 196-202.

80. Bouchardy C, Rapiti E, Blagojevic S, Vlastos AT, Vlastos G. Older female cancer patients: importance, causes, and consequences of undertreatment. J Clin Oncol 2007; 25: 1858-69.

81. Petignat P, Fioretta G, Verkooijen HM, Vlastos AT, Rapiti E, Bouchardy C, et al. Poorer survival of elderly patients with ovarian cancer: a population-based study. Surg Oncol 2004; 13: 181-6.

82. Bruchim I, Altaras M, Fishman A. Age contrasts in clinical characteristics and pattern of care in patients with epithelial ovarian cancer. Gynecol Oncol 2002; 86: 274-8.

83. Hershman D, Fleischauer AT, Jacobson JS, Grann VR, Sundararajan V, Neugut AI. Patterns and outcomes of chemo- therapy for elderly patients with stage II ovarian cancer: a population-based study. Gynecol Oncol 2004; 92: 293-9.

84. Maas HA, Kruitwagen RF, Lemmens VE, Goey SH, Janssen-Heijnen ML. The influence of age and co-morbidity on treatment and prognosis of ovarian cancer: a population-based study. Gynecol Oncol 2005; 97: 104-9.

85. Schrijvers D, Baitar A, Vos MD, Mebis J, Vroman P. Evaluation of the groningen frailty index (GFI) as a screening tool in elderly patients (PTS): an interim analysis. 2010 ESMO, Abstract 566PD.

86. Extermann M, Boler I, Reich R, Lyman GH, Brown RH, DeFelice J, et al. The chemotherapy risk assessment scale for high-age patients (CRASH) score: design and validation. 2010 ASCO Annual Meeting, Abstract 9000.

87. Hurria A, Togawa K, Mohile SG, Owusu C, Klepin HD, Gross C, et al. Predicting chemotherapy toxicity in older adults with cancer: a prospective 500 patient multicenter study. 2010 ASCO Annual Meeting, Abstract 9001.

88. McCluggage WG. Uterine carcinosarcomas (malignant mixed Mullerian tumors) are metaplastic carcinomas. Int J Gynecol Cancer 2002; 12: 687-90.

89. D'Angelo E, Prat J. Uterine sarcomas: a review. Gynecol Oncol 2010; 116: 131-9.

90. Prat J. FIGO staging for uterine sarcomas. Int J Gynaecol Obstet 2009; 104: 177-8

91. Homesley HD, Filiaci V, Markman M, Bitterman P, Eaton L, Kilgore LC, et al. Phase III trial of ifosfamide with or without paclitaxel in advanced uterine carcinosarcoma: a Gynecologic Oncology Group Study. J Clin Oncol 2007; 25: 526-31.

92. Sutton GP, Blessing JA, Rosenshein N, Photopulos G, DiSaia PJ. Phase II trial of ifosfamide and mesna in mixed mesodermal tumors of the uterus (a Gynecologic Oncology Group study). Am J Obstet Gynecol 1989; 161: 309-12.

93. Sutton G, Brunetto VL, Kilgore L, Soper JT, McGehee R, Olt G, et al. A phase III trial of ifosfamide with or without cisplatin in carcinosarcoma of the uterus: A Gynecologic Oncology Group Study. Gynecol Oncol 2000; 79: 147-53.

94. Slayton RE, Blessing JA, DiSaia PJ, Christopherson WA. Phase II trial of etoposide in the management of advanced or recurrent mixed mesodermal sarcomas of the uterus: a Gynecologic Oncology Group Study. Cancer Treat Rep 1987; 71: 661-2.

95. Omura GA, Major FJ, Blessing JA, Sedlacek TV, Thigpen JT, Creasman WT, et al. A randomized study of adriamycin with and without dimethyl triazenoimidazole carboxamide in advanced uterine sarcomas. Cancer 1983; 52: 626-32.

96. Thigpen JT, Blessing JA, Orr JW Jr, DiSaia PJ. Phase II trial of cisplatin in the treatment of patients with advanced or recurrent mixed mesodermal sarcomas of the uterus: a Gynecologic Oncology Group Study. Cancer Treat Rep 1986; 70: 271-4.

97. Curtin JP, Blessing JA, Soper JT, DeGeest K. Paclitaxel in the treatment of carcinosarcoma of the uterus: a gynecologic oncology group study. Gynecol Oncol 2001; 83: 268-70.

98. Powell MA, Filiaci VL, Rose PG, Mannel RS, Hanjani P, Degeest $\mathrm{K}$, et al. Phase II evaluation of paclitaxel and carboplatin in the treatment of carcinosarcoma of the uterus: a Gynecologic Oncology Group study. J Clin Oncol 2010; 28: 2727-31. 